\title{
POLÍTICA NACIONAL DO MEIO AMBIENTE BRASILEIRA: UMA ANÁLISE À LUZ DO CICLO DE POLÍTICAS PÚBLICAS
}

\author{
NATIONAL ENVIRONMENTAL POLICY IN BRAZIL: AN ANALYSIS IN THE LIGHT OF THE \\ PUBLIC POLICY CYCLE
}

\author{
Pollyana Martins Santos ${ }^{1}$ \\ Maria das Dores Saraiva de Loreto²
}

\section{Resumo}

Considerando uma aproximação entre a teoria das políticas públicas e a temática ambiental, o objetivo deste trabalho consistiu em analisar a Política Nacional do Meio Ambiente (PNMA) brasileira à luz do modelo do ciclo de políticas públicas proposto por Secchi (2010). Desta forma, a partir de uma perspectiva qualitativa, baseada em dados oriundos de pesquisa bibliográfica e documental, uma análise descritiva do processo político foi realizada, por meio de um estudo de caso, centrando-se nas três fases iniciais do ciclo de políticas públicas: identificação do problema; formação da agenda e formulação de alternativas. Os resultados evidenciaram que a PNMA apresenta características tanto de uma política pública do tipo regulatória, quanto constitutiva. Constatou-se que a inserção da temática ambiental na agenda política brasileira revela uma nova postura do governo no trato das questões ambientais, na qual a conciliação entre crescimento econômico e preservação ambiental é vista não apenas como possível, mas também necessária, sendo este o objetivo central da PNMA. Foram identificados na PNMA mecanismos de premiação, de coerção e de conscientização, tendo a política, na formulação das alternativas à solução dos problemas ambientais, orientação notadamente coercitiva.

Palavras-chave: Políticas Públicas. Ciclo de Políticas Públicas. Política Nacional do Meio Ambiente.

\begin{abstract}
Considering an approximation between the theory of public policies and the environmental theme, the objective of this work was to analyze the Brazilian National Environment Policy (PNMA) in the light of the public policy cycle model, proposed by Secchi (2010). Thus, from a qualitative perspective, based on data from bibliographic and documentary research, a descriptive analysis of the political process was carried out, through a case study, focusing on the three initial phases of the public policy cycle: problem identification; formation of the agenda and formulation of alternatives. The results of the research demonstrated that the PNMA presents characteristics of a public policy of a regulatory and constitutive type. It was found that the insertion of the environmental theme in the Brazilian political agenda reveals a new posture by the government in relation to environmental issues, where the reconciliation between economic growth and environmental preservation is possible and necessary, this being the central objective of PNMA. Mechanisms for rewarding, coercion and awareness were identified in the PNMA, having the policy, in the formulation of the alternatives to the solution of the environmental problems, notably coercive orientation.
\end{abstract}

Key-words: Public Policies. Public Policy Cycle. National Environment Policy.

\footnotetext{
${ }^{1}$ Possui graduação em Direito e Mestrado em Economia Doméstica e é Doutoranda pelo Programa de Pósgraduação em Economia Doméstica, todos pela Universidade Federal de Viçosa (UFV). Possui especialização em Direito Penal e Processual Penal pela Universidade Cândido Mendes . É servidora pública do Ministério Público do Estado de Minas Gerais, junto à Promotoria de Meio Ambiente e Patrimônio Público da Comarca de Viçosa.

2 Possui graduação em Economia Doméstica e em Ciências Econômicas, bem como Mestrado e Doutorado em Economia Rural, pela Universidade Federal de Viçosa, além de Pós-doutorado em Família e Meio Ambiente pela University of Guelph-Canadá. É Professora Titular do Depto de Economia Doméstica (DED/UFV).
} 


\section{INTRODUÇÃO}

De acordo com Rua e Romanini (2013), o campo das políticas públicas constitui, na atualidade, um tema de grande relevância na área das ciências políticas. Embora apontem a multiplicidade das abordagens aplicáveis à temática, as autoras destacam que uma política pública compreende, ordinariamente, vários mecanismos e procedimentos voltados para a solução pacífica de conflitos relacionados à alocação de bens e recursos públicos. Assim, considera-se que as legislações se destacam como importantes instrumentos para a materialização das políticas públicas (PINHO, 2011).

Neste contexto, a Lei 6.938, de 31 de agosto de 1981, pode ser vista como um marco no país, por ter introduzido a temática ambiental no campo das políticas públicas brasileiras. Ou seja, por meio desta lei, foi criada a Política Nacional do Meio Ambiente (PNMA), em decorrência de um contexto de mobilização mundial a favor de políticas que abordassem a questão ambiental e que possibilitassem o planejamento, controle e administração dos recursos naturais (PASSOS, 2009).

Conforme Santiago (2012), a PNMA foi cunhada como uma política orgânica, estável e de longo prazo, destinada a coordenar a aplicação das demais leis ambientais no Brasil. Nesse sentido, a mesma foi estruturada por meio de princípios, que fundamentam a gestão ambiental em nível nacional; objetivos, que orientam e conduzem as ações públicas na direção de um ambiente mais equilibrado; além de instrumentos, que viabilizam os objetivos pretendidos. Dessa forma, a PNMA se materializa através de um sistema institucional articulado, que integra as três esferas de poder no país, federal, estadual e municipal.

Em função do exposto, objetivou-se, a partir de uma aproximação entre a teoria das políticas públicas e a temática ambiental, proceder ao exame da Política Nacional do Meio Ambiente, estabelecida por meio da Lei 6.938/81, à luz do modelo do ciclo de políticas públicas, proposto por Secchi (2010).

Para tanto, baseando-se na abordagem do estilo analysis of policy (HAM; HILL, 1985), a análise foi voltada para o processo de elaboração política, centrado nas três fases iniciais do ciclo de políticas públicas, quais sejam: identificação do problema, formação da agenda e formulação de alternativas. Procurou-se, portanto, por meio de um estudo de caso, resgatar e contextualizar o cenário nacional e internacional de criação da PNMA, buscando descrever e compreender o processo político para esta política pública. 


\section{MARCO TEÓRICO}

\section{Políticas Públicas como campo de conhecimento científico}

Desde a década de 1930, estudos acadêmicos norte-americanos impulsionaram a construção de um campo disciplinar próprio das políticas públicas. De acordo com Souza (2006), Laswel (1936), considerado um dos fundadores desta área acadêmica, foi o primeiro a cunhar a expressão policy analysis, buscando agregar o conhecimento científico à atuação dos governos, o que possibilitou um primeiro passo no estabelecimento de um diálogo entre cientistas sociais, governo e grupos de interesse.

No entanto, Secchi (2010) destaca que somente na década de 50 é que duas obras fundamentais, em termos de contribuição teórica para o campo das políticas públicas, foram publicadas: em 1950, o livro The Governmental Process, de David Truman, e, em 1951, The Policy Sciences, de Daniel Lerner e Harold D. Lasswell. O autor informa que a primeira obra foi inovadora ao trabalhar a relação entre grupos de interesse, suas estruturas e técnicas de influência sobre os processos de políticas públicas nas diferentes esferas administrativas governamentais (Executivo, Legislativo, Judiciário e seus respectivos corpos burocráticos). A segunda obra, ao discutir o processo de formulação e avaliação do impacto das políticas públicas, delimitou a temática enquanto campo acadêmico multidisciplinar orientado para a resolução de problemas públicos concretos.

Posteriormente, Souza (2006) informa que outros estudos viriam a se agregar ao campo científico das políticas públicas, introduzindo conceitos fundamentais para a teoria. É o caso dos estudos de Simon (1957), Lindblom (1959, 1979) e Easton (1965), que, ao lado de Laswell (1936), são considerados os quatro "pais fundadores" da área de políticas públicas.

No Brasil, embora assuntos ligados à gestão de políticas públicas e sociais fossem rotineiramente discutidos nas áreas da Ciência Política, Sociologia, Economia ou Administração, Gelinski e Seibel (2008) ressaltam que a temática somente ganhou enfoque a partir do final dos anos 80, ocasião em que debates a respeito da redemocratização do país e as formas de gestão do orçamento público vieram à tona em decorrência da reforma constitucional de 1988. Nesse sentido, os autores destacam os trabalhos de acadêmicos como Reis (2003), Souza (2006; 2007), Faria (2003) e Melo (1999).

Não há consenso doutrinário quanto à definição do que seria política pública, havendo diversas interpretações sobre o tema (SOUZA, 2006). Contudo, Lima (2012) destaca que existem dois grandes campos teóricos em torno dos quais se distribuem os conceitos de 
políticas públicas: uma abordagem estatista, centrada em torno da figura do decisor; e uma abordagem multicêntrica, voltada para o objetivo da política pública.

Neste contexto, a abordagem estatista entende que o que determina se uma política é ou não pública é a personalidade jurídica daquele que a realiza; neste sentido, seriam políticas públicas somente as ações originárias de um órgão estatal. Esta perspectiva teórica reúne autores como Heclo (1972), Dye (1972), Mény e Thoenig (1991) e Howlett e Ramesh (2003). Já abordagem multicêntrica entende como política pública toda e qualquer ação, independentemente daquele que a executa, que seja voltada para o enfrentamento de um problema público. Nesse sentido, ao lado do Estado, organizações privadas ou não governamentais, organismos multilaterais, entre outros, também podem ser protagonistas na formulação de políticas. A esta corrente teórica filiam-se autores como Dror (1971), Kooiman (1993) e Regonini (2001).

Alinhando-se à corrente multicêntrica, Secchi (2010) aponta que dois elementos são fundamentais na compreensão das políticas públicas: a intencionalidade pública e a resposta a um problema público, de tal modo que a razão de ser de uma política pública consistiria na resolução de um problema entendido como coletivamente relevante. Assim, muito embora "não haja dúvidas de que o Estado moderno se destaque em relação a outros atores no estabelecimento de políticas públicas" (SECCHI, 2010, p. 04), ao deslocar o foco para os objetivos, o autor apresenta uma visão interpretativa mais abrangente de políticas públicas, por não restringir o seu universo autoral aos órgãos estatais.

\section{Tipologia de Políticas Públicas}

Existem diferentes modelos e formas de se entender a natureza, estrutura e intencionalidade das políticas públicas; neste sentido, podem ser mencionadas, dentre outras, as tipologias de Wilson (1983), Gormley (1986), Gustafsson (1983) e Bozeman e Pandey $(2004)^{3}$.

Contudo, uma das mais conhecidas e utilizadas tipologias consiste na proposta de Theodor Lowi (1964), também conhecida por Abordagem das Arenas. Nesta abordagem, cada um dos tipos de política corresponderia a uma arena (politics) à qual a policy deu origem, a partir da expectativa dos atores. A tipologia de Lowi baseia-se no critério do impacto esperado na sociedade e, neste sentido, poderiam ser observados quatro tipos de políticas públicas:

\footnotetext{
${ }^{3}$ Uma discussão exaustiva a respeito das tipologias das políticas públicas extrapola os objetivos deste trabalho, razão pela qual maior detalhamento sobre o tema poderá ser obtido em Secchi (2010).
} 
regulatórias, distributivas, redistributivas e constitutivas. Contudo, é preciso ressalvar que cada política pública pode agregar características de duas ou mais tipologias, o que faz com que nem sempre seja simples distinguir a linha que separa os tipos descritos por Lowi (SECCHI, 2010; RUA; ROMANINI, 2013).

Assim, por políticas regulatórias entendem-se aquelas que estabelecem padrões de comportamento, serviço ou produto para atores públicos e privados. Apropriando-se de Lowi (1964), Secchi (2010, p. 17) aponta que as políticas regulatórias "desenvolvem predominantemente dentro de uma dinâmica pluralista, em que a capacidade de aprovação ou não de uma política desse gênero é proporcional à relação de forças dos atores e interesses presentes na sociedade". Assim, consistem em exemplos de políticas regulatórias leis, orientações normativas, códigos de ética, dentre outras similares.

Por sua vez, as políticas distributivas seriam aquelas que beneficiam um grande número de pessoas, em escala relativamente pequena, e com reduzido grau de conflito (GELINSKI; SEIBEL, 2008). Secchi (2010) aponta como exemplos deste tipo de política subsídios, gratuidade de taxas para certos usuários de serviços públicos, incentivos ou renúncias fiscais, etc.

Já Souza (2006) aponta que as políticas redistributivas se enquadrariam naquelas que atingem maior número de pessoas e impõem perdas concretas, no curto prazo, para certos grupos sociais, bem como ganhos incertos, no futuro, para outros. Nesse sentido, conforme Secchi (2010), são as políticas de natureza mais conflituosa, pois representam um "jogo de soma zero". O mesmo autor ainda aponta como exemplos deste tipo de política as cotas raciais para universidade, políticas de benefícios sociais para trabalhadores e programas de reforma agrária.

Por fim, por políticas constitutivas entendem-se aquelas que lidam com procedimentos, na medida em que "são regras sobre os poderes e regras sobre as regras" (LOWI, 1985, p. 74). De acordo com Gelinski e Seibel (2008), as políticas constitutivas ou estruturadoras definem as regras do jogo e as condições em que se aplicarão as políticas distributivas, redistributivas ou regulatórias. É neste sentido que Secchi (2010, p. 18) aponta que "políticas constitutivas provocam conflitos entre os entes e os atores diretamente interessados (por exemplo, partidos, os três poderes, os níveis de governo), pois têm a capacidade de alterar o equilíbrio de poder existente". 


\section{O ciclo de políticas públicas}

De acordo com Souza (2006), diferentes modelos foram propostos com a finalidade de se entender e explicar a essência das políticas públicas. Nesse sentido, a autora cita como principais modelos o incrementalismo de Lindblom (1959), Caiden e Wildavsky (1980) e Wildavsky (1992); o modelo garbage can ou "lata de lixo", de Cohen, March e Olsen (1972); o modelo da coalização de defesa, de Sabatier e Jenkins-Smith (1993); o modelo das arenas sociais de Marques (2000); o modelo do equilíbrio interrompido, de Baumgartner e Jones (1993), e os modelos influenciados pelo novo gerencialismo público e pelo ajuste fiscal, dentre outros.

No entanto, outro modelo para análise e formulação de políticas públicas consiste no chamado ciclo de políticas públicas, onde a política pública é vista como um processo deliberativo, formado por diferentes estágios. Nesta abordagem, o enfoque é dado na definição da agenda política; ou seja, este modelo procura entender por que algumas questões entram para a agenda política em detrimento de outras (SOUZA, 2006). Na literatura, existem várias propostas de estágios do ciclo de políticas públicas, sendo que em todas elas, pelo menos três fases estão sempre presentes: formulação, implementação e controle dos impactos das políticas (FREY, 2000). Neste trabalho foi adotado o modelo de Secchi (2010), no qual são propostas seis fases para o ciclo das políticas públicas: identificação do problema; formação da agenda; formulação de alternativas; tomada de decisão; implementação; avaliação; e extinção.

Na primeira fase, de identificação do problema, o foco está centrado no surgimento de um problema público, definido pelo autor como "a diferença entre o que é e aquilo que se gostaria que fosse a realidade pública" (SECCHI, 2010, p. 34). Portanto, nesta fase, interessa ao analista investigar por que determinada situação é alçada ao status de problema público, e, portanto, passível de dar início ao ciclo de uma política pública. Assim, procura-se saber por que e quais grupos contribuíram para que fosse atribuída relevância política a uma questão específica (FREY, 2000).

A segunda fase, de formação de agenda, ocorre quando, a partir da identificação de um problema público por parte de determinados atores ou grupos políticos governamentais ou não governamentais, esta situação passa a fazer parte da agenda, entendida como um conjunto de problemas ou temas tidos como relevantes. Trata-se de uma fase que praticamente se confunde com a etapa de identificação do problema, pois representa o estreitamento da lista de problemas a serem adotados como prioridade (SILVA, 2012). Cobb e Elder (1983) apontam três condições para que um problema passe a integrar a agenda: a atenção por parte de diferentes 
atores sociais; resolubilidade, ou seja, estas ações devem ser necessárias e factíveis; e competência, isto é, o problema deve dizer respeito a uma responsabilidade pública.

A terceira fase, de formulação de alternativas, está relacionada à construção de soluções para os problemas que foram introduzidos na agenda. Nesta etapa, segundo Frey (2000), é realizado um inventário das possíveis soluções para o problema público, e onde a alternativa mais apropriada será escolhida dentre as várias opções de ação disponíveis. Secchi (2010) explica que, nesta etapa, as soluções são construídas a partir do estabelecimento de objetivos e estratégias, assim como do respectivo estudo das potenciais consequências de cada alternativa. Considerando, ainda, que cada objetivo proposto poderá ser atingindo por diferentes modos, o autor aponta que os policymakers podem adotar pelo menos quatro mecanismos de indução de comportamento: premiação (quando os comportamentos são incentivados por meio de estímulos positivos, como recompensas); coerção (quando os comportamentos são influenciados por meio de estímulos negativos, como, por exemplo, punições); conscientização (ações de cunho educativo e de apelo senso de dever moral); e soluções técnicas (quando os comportamentos são influenciados de alguma forma indireta).

A quarta fase, de tomada de decisão, remete ao momento em que os interesses dos atores são equacionados e as intenções para o enfrentamento do problema público são explicitadas. Frey (2000) esclarece que, assim como na etapa de formulação de alternativas, momentos de conflito podem marcar a tomada de decisão, sendo que a ação escolhida geralmente recairá sobre um programa de compromisso, que poderá ter sido previamente negociado entre os atores políticos mais influentes.

O quinto estágio, de implementação, é a fase em que se produzem os resultados concretos da política pública: no entender de Silva (2012), é a etapa da concretização das escolhas feitas pelos policymakers. Secchi (2010) ressalta que a fase de implementação é essencial para que se possam visualizar as limitações e falhas da política pública, além de identificar erros que antecedem a própria tomada de decisão.

A avaliação corresponde à sexta etapa do ciclo, e consiste no momento de julgamento dos resultados de uma determinada política. É importante destacar que a avaliação não se restringe a um único momento, mas sim se processa de forma contínua durante todo o ciclo da política pública, orientando o processo decisório (SILVA, 2012). O mesmo autor aponta que há diferentes abordagens para a avaliação de políticas públicas; para Secchi (2010), os mecanismos de avaliação permitem uma comparação espacial e temporal do problema e das respectivas políticas, podendo levar a três desfechos: a continuação da política, sua 
reestruturação marginal, ou sua extinção, caso o problema público tenha sido resolvido ou deixe de ter relevância política.

Por fim, o último estágio é o da extinção. Secchi (2010) aponta que estudos a respeito da extinção das políticas públicas ganharam força a partir da década de 70 , quando políticas sociais ligadas ao Welfare State foram questionadas nos países desenvolvidos. O autor aponta três razões para a extinção de uma política pública, todas ligadas ao problema inicial: pela solução do problema; pela ineficácia da política em resolver o problema; ou porque aquele problema, ainda que não resolvido, deixou de ter relevância política. No entanto, nem sempre uma política pública chega a ser extinta, já que "as políticas públicas, após um período de maturação, institucionalizam-se e criam vida própria. Não são raros casos em que uma política pública continua viva mesmo depois que o problema que a gerara já tenha sumido" (SECCHI, 2010, p. 54).

Entretanto, assim como os demais modelos, o modelo do ciclo de políticas públicas também apresenta limitações, pois, "na prática, os atores político-administrativos dificilmente se atêm a essa sequência" (SILVA, 2012, p. 229). Nesse sentido, muito embora este modelo seja uma valiosa ferramenta heurística para entendimento das políticas públicas, ele raramente reflete a real dinâmica da vida de uma política pública. Isto porque as fases geralmente se sobrepõem, dificultando a sua diferenciação. Por este motivo, diversos autores ressaltam que não é possível identificar, ao certo, um ponto de início e um ponto de finalização no ciclo da política pública, razão pela qual este ciclo é, muitas vezes, incerto (SECCHI, 2010).

No entanto, apesar destas fragilidades, a validade do ciclo de políticas públicas como modelo explicativo não é descartada, pois, desde que o analista esteja atento para estas particularidades, trata-se de um excelente instrumento para organização das ideias e para explicação de um fenômeno, por sua própria natureza, muito complexo. Assim, o modelo do ciclo de políticas públicas consiste em importante instrumento de análise, uma vez que permite o exame das fases do processo político-administrativo, no que se refere às constelações de poder, às redes políticas e sociais e às práticas político-administrativas presentes em cada estágio (FREY, 2000).

\section{PROCEDIMENTOS METODOLÓGICOS}

O presente estudo consiste numa pesquisa de natureza qualitativa e descritiva (FLICK, 2009; SAMPIERI; COLLADO; LÚCIO, 2006), que tem por objetivo, a partir de dados obtidos por meio de pesquisa bibliográfica e documental, proceder à análise da política pública 
ambiental brasileira, estabelecida por meio da Lei 6.938/81, à luz do modelo do ciclo de política públicas proposto por Secchi (2010).

Representa, portanto, uma abordagem no estilo analysis of policy (HAM; HILL, 1985), com foco nas fases iniciais do ciclo de políticas públicas: identificação do problema; formação da agenda e formulação de alternativas. Nesse sentido, a pesquisa compreendeu um estudo de caso $^{4}$, centrando-se nas seguintes questões:

- Identificação da tipologia na qual se enquadra a PNMA, dentro da abordagem proposta por Lowi (1964);

- Descrição e contextualização das três fases iniciais do ciclo de políticas públicas da PNMA: identificação do problema, formação da agenda e formulação de alternativas.

Conforme asseveram Secchi (2010) e Silva (2012), as fases da identificação do problema e formação da agenda são muito próximas, praticamente se confundindo, razão pela qual estes dois estágios foram abordados conjuntamente.

\section{RESULTADOS E DISCUSSÃO}

Tendo como estudo de caso a Política Nacional do Meio Ambiente (PNMA), os resultados foram discutidos considerando os seguintes tópicos: Identificação da Tipologia da PNMA e Descrição do Ciclo Político do PNMA.

\section{Identificação da Tipologia da PNMA}

A Política Nacional de Meio Ambiente (PNMA) foi instituída no Brasil através da Lei 6.938, de 31 de agosto de 1981. Por meio deste dispositivo legal, a questão ambiental foi juridicamente incorporada à gestão das políticas públicas brasileiras, sendo fundamental para a inserção de um capítulo específico referente ao meio ambiente na Constituição Federal de 1.988 (SALHEB et al., 2009; BARROS et al., 2012).

Assim, tomando como parâmetro a tipologia de Lowi (1964), a PNMA consiste numa política pública regulatória, já que a mesma, ao estabelecer as diretrizes públicas ambientais brasileiras, estabelece imperativos (obrigatoriedades), interdições e condições por meio das

\footnotetext{
${ }^{4}$ Caracteriza-se como um estudo de um caso/evento de forma longitudinal, que pode ser pode ser exploratório, descritivo ou explanatório (YIN, 2009).
} 
quais podem e devem ser realizadas determinadas atividades e admitidos certos comportamentos (RUA; ROMANINI, 2013).

Observa-se, ainda, que a PNMA também estabelece normas gerais a serem aplicadas pela União, Estados, Municípios e Distrito Federal na regulamentação das questões ambientais em suas respectivas áreas de jurisdição, delimitando, assim, a ação destes entes, conforme disposição constante na Exposição de Motivos $^{5}$ da Lei 6.938/81. A orientação expressa no documento foi incorporada no artigo $5^{\circ}$ da Lei 6.938/81, estendendo a obrigatoriedade de observância das diretrizes da PNMA não apenas aos entes da Federação, como também a todas as atividades empresariais, públicas ou privadas, no país:

O referido Anteprojeto, contendo normas gerais a serem aplicadas pela União, Estados, Distrito Federal, Territórios Federais e Municípios, tem por fundamento o art. 80, item $\mathrm{XVII}$, alíneas $\mathrm{c}, \mathrm{h} \mathrm{e} \mathrm{i,} \mathrm{da} \mathrm{Constituição,} \mathrm{posto} \mathrm{que} \mathrm{as} \mathrm{normas} \mathrm{relativas} \mathrm{à} \mathrm{proteção}$ ambiental interessam, diretamente, à defesa e proteção da saúde e dos recursos naturais, sendo assim, sem dúvida, matéria de competência da União, não excluída todavia, a competência dos Estados para, no que concerne à alínea c, legislar, supletivamente, na forma prevista no parágrafo único do mencionado dispositivo constitucional (BRASIL, 1981, p. 09).

Art. 5o - As diretrizes da Política Nacional do Meio Ambiente serão formuladas em normas e planos, destinados a orientar a ação dos Governos da União, dos Estados, do Distrito Federal, dos Territórios e dos Municípios no que se relaciona com a preservação da qualidade ambiental e manutenção do equilíbrio ecológico, observados os princípios estabelecidos no art. $2^{\circ}$ desta Lei. Parágrafo único - As atividades empresariais públicas ou privadas serão exercidas em consonância com as diretrizes da Política Nacional do Meio Ambiente (BRASIL, 1981).

Considerando que a PNMA também estabelece normas e procedimentos sobre os quais devem ser implementadas as demais políticas públicas ambientais eventualmente editadas no país, tanto no campo público quanto privado, ela também pode ser entendida não apenas como uma política pública do tipo regulatória, mas que também agrega características das políticas constitutivas ou estruturadoras (GELINSKI; SEIBEL, 2008; SECCHI, 2010).

Dessa forma, a PNMA, em função das suas diretrizes e normas gerais, se caracteriza por ser regulatória e, ao mesmo tempo, constitutiva, por instituir padrões de comportamentos e orientações normativas, como também estabelecer regras sobre os poderes e sobre o jogo político.

\footnotetext{
${ }^{5}$ A exposição de motivos é o documento oficial que acompanha o texto da lei, com o objetivo de explicar a proposta e/ou expor as razões de se editar a norma. Informação constante no site da Câmara dos Deputados. Disponível em: http://www2.camara.leg.br/participe/fale-conosco/perguntas-frequentes/processo-legislativo\#\#6. Acesso em: 24 fev. 2020.
} 


\section{Descrição do Ciclo Político da PNMA}

Na descrição do Ciclo Político da PNMA, procurou-se, inicialmente, examinar como o problema foi identificado e sua incorporação na agenda política.

\section{Identificação do Problema e Formação da Agenda}

Conforme pontuam Santiago (2012) e Barros et al. (2012), até meados da década de 60, a temática ambiental no mundo praticamente não possuía contornos próprios, como nos moldes contemporâneos. Até então, vigorava um pensamento hegemônico utilitarista, segundo o qual o desenvolvimento se reduziria ao crescimento econômico, predominando um cenário de exploração predatória no planeta.

Desta forma, até aquele momento, a questão ambiental não possuía relevância política no cenário internacional a ponto de ser objeto de uma política pública. Não porque não se constituísse numa situação insatisfatória, uma vez que, conforme postula Viola (1987), a poluição e os impactos ambientais provenientes deste modelo exploratório eram visíveis. Mas porque, a despeito disso, estes efeitos negativos eram encarados como inevitáveis e também justificáveis diante dos benefícios proporcionados pelo crescimento econômico. Portanto, até então, a temática ambiental no mundo consistia numa demanda reprimida, dado que era uma situação insatisfatória, mas diante da qual a sociedade se acomodava (RUA; ROMANINI, 2013).

Entretanto, o uso irracional dos recursos naturais, para atender ao crescimento econômico, provocou uma contínua e intensa degradação do meio ambiente, levando a que, a partir da década de 70, surgissem novas propostas e formas de se pensar a questão ambiental no cenário internacional (SALHEB et al., 2009; BARROS et al., 2012). Assim, teve início um processo de desnaturalização da questão ambiental no mundo (ACSELRAD, 2010), deixando a temática de consistir num estado de coisas, para ser reconhecida como um problema político, conforme processo descrito por Rua e Romanini (2013).

Este movimento mundial foi impulsionado principalmente pela publicação do relatório "Os limites do crescimento", pelo Clube de Roma, bem como pela realização da Conferência das Nações Unidas Sobre o Meio Ambiente (Declaração de Estocolmo), ambos em 1972. De acordo com Salheb et al. (2009), o relatório publicado pelo Clube de Roma - uma organização não governamental fundada em 1969 - previa um colapso total do sistema global até meados do século XXI, em decorrência do crescimento econômico desenfreado, propondo o congelamento do crescimento econômico das nações na fase em que se encontrava à época. 
Por sua vez, a Conferência das Nações Unidas, realizada em Estocolmo, Suécia, reuniu chefes de Estado de todo o planeta para debaterem as questões ambientais, ocasião em que se formaram dois grupos de países: os países desenvolvidos, que apoiavam a proposta contida no relatório do Clube de Roma, e os países periféricos, dentre eles o Brasil, que se opunham ao documento, já que, por estarem em fase de desenvolvimento, não tinham interesse em apoiar uma proposta de crescimento zero (SALHEB et al., 2009).

Apesar da polêmica gerada pelo Relatório, a Conferência de Estocolmo foi um marco na mudança de pensamento a respeito do meio ambiente, pois representou a tentativa, até então inédita, de aproximação entre direitos humanos e meio ambiente (SANTIAGO, 2012). Ainda segundo a autora, na ocasião foram produzidos 26 princípios, todos voltados para a preocupação em racionalizar o uso dos recursos naturais e compatibilizar a produção econômica e qualidade de vida para as gerações atuais e futuras - o que viria a fundamentar o conceito de desenvolvimento sustentável, anos depois.

Paralelamente, é também na década de 70 que teve início o processo de disseminação de um dos movimentos sociais mais proeminentes no cenário mundial: o movimento ambientalista (CASTELLS, 2008), fato que pode ser entendido, na visão de Viola (1987), como um marco no surgimento de uma "consciência ambiental" mundial.

Contudo, entre as décadas de 50 e 70, o Brasil vivenciava o auge do "milagre econômico brasileiro", marcado pela exploração irrestrita dos recursos naturais e desbravamento dos territórios. Nesta época, os investimentos públicos eram destinados, principalmente, para as áreas de petróleo, energia, siderurgia e infraestrutura, não havendo maiores preocupações com os imensos impactos ambientais produzidos com as obras faraônicas que caracterizaram o período e, especialmente, com o processo de devastação da Amazônia (SANTIAGO, 2012).

Logo, até então não era possível se falar, no Brasil, da existência de uma política pública de caráter ambiental. O assunto era tratado de forma esparsa na legislação, como, por exemplo, o Código das Águas e o Código Florestal, de 1934, e o Código da Fauna e o Código de Mineração, em 1967. No entanto, a tutela legal se restringia àquilo que representasse interesse econômico, sob um viés utilitarista dos recursos naturais. Desta feita, ainda não era visível que a questão ambiental tivesse deixado a condição de estado de coisas para se tornar efetivamente um problema público, dado que, na prática, conforme Salheb et al. (2009), observava-se claramente que o Poder Público priorizava o capital e a economia em detrimento da proteção ambiental. 
Assim, não há como negar que o contexto mundial foi determinante para a inserção da temática ambiental na agenda política do Brasil. Até então, a posição brasileira em termos de temática ambiental estava dissociada da noção de preservação ambiental que crescia no mundo. Salheb et al. (2009) informam que, na Conferência de Estocolmo, o Brasil liderava o posicionamento de que era necessário poluir para que pudesse haver crescimento econômico. Contudo, a conjugação da pressão de organismos internacionais, ação de movimentos conservacionistas e demandas externas pela preservação ambiental (SALHEB et al., 2009; BARROS et al., 2012) deram início a um processo, ainda que tímido, de reconhecimento da importância pública da questão ambiental no país.

Nesse contexto é que, em 1973, foi criada, no Brasil, no âmbito do Ministério do Interior, a Secretaria Especial de Meio Ambiente (SEMA). À época, a SEMA coordenava, de forma descentralizada, a gestão ambiental brasileira, atuando por meio de órgãos estaduais e municipais nos estados de maior desenvolvimento, como Rio de Janeiro e São Paulo (SANTIAGO, 2012). Contudo, ainda refletia uma visão distanciada em termos de proteção ambiental, dado que, conforme ressalva Viola (1987), a sua criação foi uma iniciativa meramente formal, mais para atender às exigências de organismos internacionais (que colocavam como condicionante para a concessão de empréstimos a criação de órgãos dessa natureza no país) do que decorrente de uma verdadeira preocupação ambiental dos governantes.

Paralelos às pressões externas, em 1974 surgem, no Brasil, os primeiros contornos de um movimento ecológico (VIOLA, 1987), insuflado, conforme Santiago (2012), pelos conflitos decorrentes da extrema concentração de renda decorrente do período desenvolvimentista brasileiro. Assim, como aponta Viola (1987), foi um marco deste período a criação da Associação Gaúcha de Proteção ao Ambiente Natural (AGAPAN), primeira organização desta natureza na América Latina. De acordo com o autor, a AGAPAN tinha como pontos fundamentais a defesa da fauna e da vegetação; o combate ao uso exagerado dos meios mecânicos contra o solo e à poluição causada pelas indústrias e veículos; o combate ao uso indiscriminado de inseticidas, fungicidas e herbicidas; o combate à poluição dos cursos d'água pelos resíduos industriais e domiciliares não-tratados; 0 combate às destruições desnecessárias de belezas paisagísticas; e a luta pela salvação da humanidade da destruição, promovendo a ecologia como ciência da sobrevivência e difundindo uma nova moral ecológica. Posteriormente, ainda em 1974, a liberalização política criou um ambiente propício ao surgimento de outras organizações ecológicas no país, especialmente no Sul-Sudeste, destacando-se, dentre elas, o Movimento pela Arte e Pensamento Ecológico, em São Paulo. 
É desta forma que a pressão internacional, aliada ao crescimento dos movimentos ecológicos no interior do país, acabam por culminar, em 1981, na edição da Lei 6.938, de 31 de agosto de 1981. De acordo com Souza (2006), é o momento em que o governo brasileiro reconhece a necessidade de dar respostas às demandas ambientalistas, que vinham sendo colocadas pela sociedade, incluindo o tema na agenda política. Neste momento, foi criada no país uma política pública de cunho ambiental, sendo, então, ratificada a Conferência de Estocolmo, da qual o Brasil fora signatário.

É importante destacar que, muito embora as políticas constitutivas se caracterizem pela relação conflituosa entre os atores sociais envolvidos, a Lei 6.938/81 se desenvolveu num cenário de quase consenso: idealizada sob o governo do último presidente militar no país, o general João Figueiredo, a PNMA agregou governistas e oposição, sendo aprovada quase por unanimidade, com apenas 02 votos contrários ${ }^{6}$.

Observa-se, assim, que com a edição da Lei 6.938/81 são atendidas as três condições apontadas por Cobb e Elder (1983) para que uma determinada temática passe a integrar a agenda política: pressão por parte de diferentes atores sociais (o que, no caso da PNMA, se observou tanto no cenário nacional quanto internacional); resolubilidade, ou seja, a proteção ambiental passou a ser vista como uma ação necessária e possível; e a competência, pois a questão ambiental deixou de ser tratada como uma questão secundária para ser encarada efetivamente como uma questão de ordem pública.

\section{Formulação de alternativas}

A questão ambiental, uma vez inserida na agenda pública brasileira, demandava a construção de soluções: neste sentido, a PNMA estabeleceu uma série de instrumentos que viabilizassem o alcance dos objetivos almejados com a política - em última instância, a conciliação entre crescimento econômico e preservação ambiental. É o que se observa da Exposição de Motivos da Lei 6.938/81:

Os dispositivos referentes à política nacional do meio ambiente instituem os princípios dessa política, indicando a conduta a ser seguida diante da problemática ambiental, além de estabelecer suas diretrizes, visando a compatibilização do desenvolvimento econômico-social com a preservação da qualidade do meio ambiente e do equilíbrio ecológico. Preveem, ainda, determinações de critérios, normas e padrões de qualidade dos recursos naturais, visando sua melhor utilização no processo de desenvolvimento.

\footnotetext{
${ }^{6}$ Informações constantes na reportagem "25 anos de PNMA - a lei que implantou nossa política ambiental atinge a maioridade". Disponível em: http://www.ambientelegal.com.br/25-anos-a-lei-que-implantou-nossa-politicaambiental-atinge-a-maturidade/. Acesso em: 24 fev. 2020.
} 
Observa-se, dessa maneira, uma nova postura do governo brasileiro no trato das questões ambientais: na perspectiva da PNMA, a preservação do meio ambiente não é mais vista como um entrave ao desenvolvimento. Pelo contrário, a preservação do meio ambiente seria o meio para se alcançar o desenvolvimento socioeconômico. Esta nova leitura da temática ambiental foi recepcionada no artigo $2^{\circ}$ da Lei $6.938 / 81$, que estabelece o objetivo geral da PNMA:

Art. $2^{\circ}$ - A Política Nacional do Meio Ambiente tem por objetivo a preservação, melhoria e recuperação da qualidade ambiental propícia à vida, visando assegurar, no País, condições ao desenvolvimento sócio-econômico, aos interesses da segurança nacional e à proteção da dignidade da vida humana, atendidos os seguintes princípios.

Assim, partindo dessa nova abordagem, a PNMA discrimina, em seu artigo $4^{\circ}$, uma série de objetivos específicos a serem alcançados pela política pública, de modo a atender ao objetivo geral proposto no artigo $2^{\circ}$, sendo eles:

Art. 4ํ- A Política Nacional do Meio Ambiente visará:

I - à compatibilização do desenvolvimento econômico social com a preservação da qualidade do meio ambiente e do equilíbrio ecológico;

II - à definição de áreas prioritárias de ação governamental relativa à qualidade e ao equilíbrio ecológico, atendendo aos interesses da União, dos Estados, do Distrito Federal, do Territórios e dos Municípios

III - ao estabelecimento de critérios e padrões da qualidade ambiental e de normas relativas ao uso e manejo de recursos ambientais;

IV - ao desenvolvimento de pesquisas e de tecnologias nacionais orientadas para o uso racional de recursos ambientais;

$\mathrm{V}$ - à difusão de tecnologias de manejo do meio ambiente, à divulgação de dados e informações ambientais e à formação de uma consciência pública sobre a necessidade de preservação da qualidade ambiental e do equilíbrio ecológico;

VI - à preservação e restauração dos recursos ambientais com vistas à sua utilização racional e disponibilidade permanente, concorrendo para a manutenção do equilíbrio ecológico propício à vida;

VII - à imposição, ao poluidor e ao predador, da obrigação de recuperar e/ou indenizar os danos causados, e ao usuário, de contribuição pela utilização de recursos ambientais com fins econômicos.

Já no que concerne à aplicação da PNMA, a exposição de motivos da Lei 6.938/81 traça a linha de ação de cada um dos entes da Federação para alcance dos objetivos estabelecidos, nos seguintes termos:

Por seus objetivos, fica determinado, em linhas gerais, que a ação do Governo Federal será, sobretudo, normativa e coordenadora, cabendo preferencialmente aos Estados, Distrito Federal, Territórios e Municípios, tarefas executivas. À União se reserva o direito de exercer, supletivamente, ações de caráter executivo, se por alguma razão essas não puderem ser realizadas satisfatoriamente pelas demais esferas governamentais. 
Para tanto, o artigo $6^{\circ}$ da Lei 6.938/81 instituiu o Sistema Nacional de Meio Ambiente (SISNAMA), um complexo administrativo de coordenação de políticas públicas ambientais envolvendo os três níveis da Federação, com objetivo dar concretude à PNMA, como exposto por Brasil (1981):

Art. 6ํㅡ - Os órgãos e entidades da União, dos Estados, do Distrito Federal, dos Territórios e dos Municípios, bem como as fundações instituídas pelo Poder Público, responsáveis pela proteção e melhoria da qualidade ambiental, constituirão o Sistema Nacional do Meio Ambiente - SISNAMA, assim estruturado:

I - órgão superior: o Conselho de Governo, com a função de assessorar o Presidente da República na formulação da política nacional e nas diretrizes governamentais para 0 meio ambiente e os recursos ambientais;

II - órgão consultivo e deliberativo: o Conselho Nacional do Meio Ambiente (CONAMA), com a finalidade de assessorar, estudar e propor ao Conselho de Governo, diretrizes de políticas governamentais para o meio ambiente e os recursos naturais e deliberar, no âmbito de sua competência, sobre normas e padrões compatíveis com o meio ambiente ecologicamente equilibrado e essencial à sadia qualidade de vida;

III - órgão central: a Secretaria do Meio Ambiente da Presidência da República, com a finalidade de planejar, coordenar, supervisionar e controlar, como órgão federal, a política nacional e as diretrizes governamentais fixadas para o meio ambiente;

IV - órgãos executores: o Instituto Brasileiro do Meio Ambiente e dos Recursos Naturais Renováveis - IBAMA e o Instituto Chico Mendes de Conservação da Biodiversidade Instituto Chico Mendes, com a finalidade de executar e fazer executar a política e as diretrizes governamentais fixadas para o meio ambiente, de acordo com as respectivas competências;

V - Órgãos Seccionais: os órgãos ou entidades estaduais responsáveis pela execução de programas, projetos e pelo controle e fiscalização de atividades capazes de provocar a degradação ambiental;

VI - Órgãos Locais: os órgãos ou entidades municipais, responsáveis pelo controle e fiscalização dessas atividades, nas suas respectivas jurisdições.

$\S 1^{\circ}$ - Os Estados, na esfera de suas competências e nas áreas de sua jurisdição, elaborarão normas supletivas e complementares e padrões relacionados com o meio ambiente, observados os que forem estabelecidos pelo CONAMA.

$\S 2^{\circ}$ Os Municípios, observadas as normas e os padrões federais e estaduais, também poderão elaborar as normas mencionadas no parágrafo anterior.

De acordo com Antunes (2000), a criação do SISNAMA foi fruto de influência externa, sendo o mesmo estruturado pelos policymakers nos moldes da National Environmental Policy Act (NEPA), legislação ambiental norte-americana promulgada em 10 de janeiro de 1970, considerada a norma precursora do desenvolvimento da política ambiental nos Estados Unidos $^{7}$. Isto porque, a exemplo da norma americana, o SISNAMA tem como finalidade estabelecer uma rede de agências governamentais, nos três níveis da Federação, visando implantar nacionalmente uma política pública de meio ambiente.

Conforme pontua Milaré (2009), a estrutura organizacional do SISNAMA permite a participação também de instituições não-governamentais por meio dos canais competentes. Desta forma, é possível observar a presença de uma orientação multicêntrica na PNMA, dado

7 Informações presentes no site da EPA - US Environmental Protection Agency. Disponível em: https://www.epa.gov/nepa/what-national-environmental-policy-act. Acesso em: 24 fev. 2020. 
que a norma admite a participação de agentes não-governamentais na elaboração da política pública ambiental no país, não restringindo a ação apenas aos órgãos do governo.

$\mathrm{Na}$ escolha das alternativas, outra estratégia empregada pelos policymakers para assegurar a obtenção dos resultados pretendidos com a PNMA foi a criação de Instrumentos da Política Nacional de Meio Ambiente. Assim, conforme previsão constante na Exposição de Motivos da Lei 6.938/81, pontua-se que:

São considerados, no Anteprojeto, como instrumentos da política nacional do meio ambiente, o licenciamento de atividades efetiva ou potencialmente poluidoras, a concessão ou suspensão de incentivos e financiamentos, as penalidades pelo não cumprimento das medidas necessárias à preservação ou correção da degradação ambiental, e o Cadastro Técnico Federal das Atividades e Instrumentos de Defesa Ambiental.

A orientação contida na Exposição de Motivos foi incorporada à Lei 6.938/81 em seu artigo $9^{\circ}$, que assim estabelece:
Art. 9ำ - São instrumentos da Política Nacional do Meio Ambiente:
I - o estabelecimento de padrões de qualidade ambiental;
II - o zoneamento ambiental;
III - a avaliação de impactos ambientais;
IV - o licenciamento e a revisão de atividades efetiva ou potencialmente poluidoras;
$\mathrm{V}$ - os incentivos à produção e instalação de equipamentos e a criação ou absorção de tecnologia, voltados para a melhoria da qualidade ambiental;
VI - a criação de reservas e estações ecológicas, áreas de proteção ambiental e as de relevante interesse ecológico, pelo Poder Público Federal, Estadual e Municipal;
VI - a criação de espaços territoriais especialmente protegidos pelo Poder Público federal, estadual e municipal, tais como áreas de proteção ambiental, de relevante interesse ecológico e reservas extrativistas;
VII - o sistema nacional de informações sobre o meio ambiente;
VIII - o Cadastro Técnico Federal de Atividades e Instrumentos de Defesa Ambiental;
IX - as penalidades disciplinares ou compensatórias ao não cumprimento das medidas necessárias à preservação ou correção da degradação ambiental.
$X$ - a instituição do Relatório de Qualidade do Meio Ambiente, a ser divulgado anualmente pelo Instituto Brasileiro do Meio Ambiente e Recursos Naturais Renováveis - IBAMA;
XI - a garantia da prestação de informações relativas ao Meio Ambiente, obrigando-se o Poder Público a produzi-las, quando inexistentes;
XII - o Cadastro Técnico Federal de atividades potencialmente poluidoras e/ou utilizadoras dos recursos ambientais.
XIII - instrumentos econômicos, como concessão florestal, servidão ambiental, seguro ambiental e outros.

Conforme Milaré (2009), estes instrumentos representam os mecanismos legais e institucionais postos à disposição da Administração Pública para obtenção dos objetivos previstos na PNMA, sendo fundamentais para a sua efetividade. Silva (1995) distribui estes instrumentos em três grupos distintos, conforme esquema do Quadro 1: 


\section{Quadro 1. Tipologia dos Instrumentos previstos na PNMA}

\begin{tabular}{|l|l|c|}
\hline \multicolumn{1}{|c|}{ Grupo } & \multicolumn{1}{|c|}{ Finalidade } & $\begin{array}{l}\text { Instrumentos art. 90 da } \\
\text { Lei 6.938/81 }\end{array}$ \\
\hline $\begin{array}{l}\text { 1. Instrumentos de Intervenção } \\
\text { ambiental }\end{array}$ & $\begin{array}{l}\text { Mecanismos condicionadores das condutas e } \\
\text { atividades relacionadas ao meio ambiente }\end{array}$ & I, II, III, IV e VI \\
\hline $\begin{array}{l}\text { 2. Instrumentos de controle } \\
\text { ambiental }\end{array}$ & $\begin{array}{l}\text { Medidas tomadas pelo Poder Público a fim de } \\
\text { verificar se pessoas públicas ou particulares se } \\
\text { adequaram às normas e padrões de qualidade } \\
\text { ambiental, e que podem ser anteriores, simultâneas } \\
\text { ou posteriores à ação em questão }\end{array}$ & VII, VIII, X e IV \\
\hline $\begin{array}{l}\text { 3. Instrumentos de controle } \\
\text { repressivo }\end{array}$ & $\begin{array}{l}\text { Medidas sancionatórias aplicáveis à pessoa física ou } \\
\text { jurídica }\end{array}$ & \multicolumn{1}{|c|}{ IX } \\
\hline
\end{tabular}

Fonte: Adaptado de Silva (1995).

$\mathrm{Na}$ formulação de alternativas para o alcance dos objetivos propostos na PNMA, os policymakers, no contexto da política ambiental brasileira, adotam mecanismos do tipo premiação, coerção e conscientização.

Com relação aos mecanismos de premiação, a PNMA adotou esta estratégia em duas situações: no artigo $9^{\circ}$, V, e no artigo $9^{\circ}-B, \S 2^{\circ}$ :

Art. $9^{\circ}, \mathrm{V}$ - os incentivos à produção e instalação de equipamentos e a criação ou absorção de tecnologia, voltados para a melhoria da qualidade ambiental;

Art. $9^{\circ}$-B, $\S 20$ - A servidão ambiental perpétua equivale, para fins creditícios, tributários e de acesso aos recursos de fundos públicos, à Reserva Particular do Patrimônio Natural RPPN, definida no art. 21 da Lei no 9.985, de 18 de julho de 2000.

No primeiro caso, um dos exemplos pode ser encontrado na certificação ISO 14001:2015, uma norma internacional editada pela ISO (Organização Internacional para a Normalização), que trata de Sistemas de Gestão Ambiental. Esta norma foi idealizada com o propósito de compatibilizar a proteção ambiental e prevenção à poluição com o crescimento socioeconômico de uma organização. É direcionada e aplicável a qualquer empresa, independentemente de seu tamanho, porte ou segmento de atividade, seja ele industrial, comercial ou de serviços, que atesta que a empresa, uma vez certificada, passa a ser caracterizada como uma organização capaz de identificar e administrar seus impactos ambientais, melhorar suas operações, reduzir custos e minimizar riscos de responsabilidades ambientais. No Brasil, cabe ao INMETRO auditar e emitir a certificação da ISO 14001:2015 (ABNT, 2015).

Já com relação à hipótese prevista no artigo $9^{\circ}-\mathrm{B}, \S^{\circ}$, Milaré $(2009$, p. 882) assevera que a servidão ambiental "envolve, basicamente, a renúncia voluntária do proprietário rural, ao direito de uso, exploração ou supressão dos recursos naturais existentes em determinado prédio particular". Isto significa uma maior preservação do meio ambiente e dos recursos 
naturais, razão pela qual, como forma de incentivar a implantação do instituto dentre os proprietários rurais, a PNMA assegura ao instituidor benefícios econômicos indiretos, personificados na concessão de crédito em situação mais vantajosa ou pelo enquadramento tributário diferenciado.

Já no que concerne aos mecanismos de conscientização, a PNMA fez uso desta estratégia em pelo menos cinco situações: artigo $2^{\circ}$, VI e X; artigo $4^{\circ}$, IV e V; e artigo 13 :

Art. 2ํ- - A Política Nacional do Meio Ambiente tem por objetivo a preservação, melhoria e recuperação da qualidade ambiental propícia à vida, visando assegurar, no País, condições ao desenvolvimento sócio-econômico, aos interesses da segurança nacional e à proteção da dignidade da vida humana, atendidos os seguintes princípios:

$\mathrm{VI}$ - incentivos ao estudo e à pesquisa de tecnologias orientadas para o uso racional e a proteção dos recursos ambientais;

$X$ - educação ambiental a todos os níveis de ensino, inclusive a educação da comunidade, objetivando capacitá-la para participação ativa na defesa do meio ambiente.

Art. 4ํ - A Política Nacional do Meio Ambiente visará:

IV - ao desenvolvimento de pesquisas e de tecnologias nacionais orientadas para o uso racional de recursos ambientais;

$\mathrm{V}$ - à difusão de tecnologias de manejo do meio ambiente, à divulgação de dados e informações ambientais e à formação de uma consciência pública sobre a necessidade de preservação da qualidade ambiental e do equilíbrio ecológico;

Art. 13. - O Poder Executivo incentivará as atividades voltadas ao meio ambiente, visando:

I - ao desenvolvimento, no País, de pesquisas e processos tecnológicos destinados a reduzir a degradação da qualidade ambiental;

II - à fabricação de equipamentos antipoluidores;

III - a outras iniciativas que propiciem a racionalização do uso de recursos ambientais.

Parágrafo único - Os órgãos, entidades, e programas do Poder Público, destinados ao incentivo das pesquisas científicas e tecnológicas, considerarão, entre as suas metas prioritárias, o apoio aos projetos que visem a adquirir e desenvolver conhecimentos básicos e aplicáveis na área ambiental e ecológica.

Assim sendo, a PNMA inseriu medidas de cunho educacional, tanto no capítulo referente aos princípios norteadores da política pública (art. $2^{\circ}$ ), quanto no capítulo referente aos objetivos (art. $4^{\circ}$ ), duas seções estratégicas da norma. Além disso, no artigo 13, os policymakers procuram incentivar a criação de instrumentos tecnológicos que deem suporte à área ambiental, determinando que a questão seja tratada de forma prioritária pelos governos.

Por fim, estão presentes na PNMA também mecanismos de coerção, que procuram penalizar os comportamentos incompatíveis com os princípios da política. Pode-se afirmar que estes mecanismos receberam maior atenção por parte dos policymakers, uma vez que, ao contrário dos mecanismos de premiação e conscientização, foram expressamente mencionados na Exposição de Motivos da Lei 6.938/81:

Finalmente, cabe evidenciar que as penalidades estabelecidas no Anteprojeto são as mesmas da legislação atual, com apenas duas inovações, consubstanciadas na 
possibilidade de perdas e incentivos e benefícios fiscais ou de participação em linhas de financiamento.

Desta forma, os mecanismos de coerção foram recepcionados em pelo menos seis situações na PNMA, que estabeleceu sanções de natureza administrativa, civil e criminal para comportamentos lesivos ao meio ambiente, conforme previsão dos artigos $4^{\circ}$, VII, art. $8^{\circ}$, V; art. $9^{\circ}, \mathrm{IX}$, art. 14 e art. 15 :

Art. 4ํ- - A Política Nacional do Meio Ambiente visará:

VII - à imposição, ao poluidor e ao predador, da obrigação de recuperar e/ou indenizar os danos causados e, ao usuário, da contribuição pela utilização de recursos ambientais com fins econômicos.

Art. $8^{\circ}$ Compete ao CONAMA:

$\mathrm{V}$ - determinar, mediante representação do IBAMA, a perda ou restrição de benefícios fiscais concedidos pelo Poder Público, em caráter geral ou condicional, e a perda ou suspensão de participação em linhas de financiamento em estabelecimentos oficiais de crédito;

Art. 9 - São instrumentos da Política Nacional do Meio Ambiente:

IX - as penalidades disciplinares ou compensatórias ao não cumprimento das medidas necessárias à preservação ou correção da degradação ambiental.

Art. 14. - Sem prejuízo das penalidades definidas pela legislação federal, estadual e municipal, o não cumprimento das medidas necessárias à preservação ou correção dos inconvenientes e danos causados pela degradação da qualidade ambiental sujeitará os transgressores:

I - à multa simples ou diária, nos valores correspondentes, no mínimo, a 10 (dez) e, no máximo, a 1.000 (mil) Obrigações Reajustáveis do Tesouro Nacional - ORTNs, agravada em casos de reincidência específica, conforme dispuser o regulamento, vedada a sua cobrança pela União se já tiver sido aplicada pelo Estado, Distrito Federal, Territórios ou pelos Municípios.

II - à perda ou restrição de incentivos e benefícios fiscais concedidos pelo Poder Público; III - à perda ou suspensão de participação em linhas de financiamento em estabelecimentos oficiais de crédito;

IV - à suspensão de sua atividade.

$\S 11^{\circ}$ - Sem obstar a aplicação das penalidades previstas neste artigo, é o poluidor obrigado, independentemente da existência de culpa, a indenizar ou reparar os danos causados ao meio ambiente e a terceiros, afetados por sua atividade. O Ministério Público da União e dos Estados terá legitimidade para propor ação de responsabilidade civil e criminal, por danos causados ao meio ambiente.

$\S 2^{\circ}$ - No caso de omissão da autoridade estadual ou municipal, caberá ao Secretário do Meio Ambiente a aplicação das penalidades pecuniárias previstas neste artigo.

$\S$ 3으 - Nos casos previstos nos incisos II e III deste artigo, o ato declaratório da perda, restrição ou suspensão será atribuição da autoridade administrativa ou financeira que concedeu os benefícios, incentivos ou financiamento, cumprindo resolução do CONAMA. $\S 50 \mathrm{~A}$ execução das garantias exigidas do poluidor não impede a aplicação das obrigações de indenização e reparação de danos previstas no $\S 10$ deste artigo.

Art. 15. O poluidor que expuser a perigo a incolumidade humana, animal ou vegetal, ou estiver tornando mais grave situação de perigo existente, fica sujeito à pena de reclusão de 1 (um) a 3 (três) anos e multa de 100 (cem) a 1.000 (mil) MVR.

$\S 11^{\circ}$ A pena e aumentada até o dobro se:

I - resultar:

a) dano irreversível à fauna, à flora e ao meio ambiente;

b) lesão corporal grave;

II - a poluição é decorrente de atividade industrial ou de transporte;

III - o crime é praticado durante a noite, em domingo ou em feriado. 
$\S 2^{\circ}$ Incorre no mesmo crime a autoridade competente que deixar de promover as medidas tendentes a impedir a prática das condutas acima descritas.

Outro aspecto importante pode ser observado no artigo 14, $\S 1^{\circ}$ : neste dispositivo, os policymakers adotaram a teoria da responsabilidade ambiental objetiva; ou seja, o causador do dano ambiental será responsabilizado, independentemente da existência de culpa, sendo suficientes a ocorrência do dano e do nexo causal entre conduta e dano (SILVEIRA, 2004; LANFREDI, 2001). Desta forma, a PNMA estabelece uma penalização mais rigorosa, procurando coibir a ocorrência de atos lesivos ao meio ambiente.

\section{CONSIDERAÇÕES FINAIS}

No presente artigo, a partir de uma abordagem que procurou aproximar a teoria das políticas públicas à temática ambiental, examinou-se a política pública ambiental brasileira à luz do modelo do ciclo de políticas públicas proposto por Secchi (2010).

Nesse sentido, os resultados demonstraram que a PNMA apresenta características de uma política pública dos tipos regulatória e constitutiva, por se tratar de uma lei de alcance nacional, que estabelece normas e procedimentos sobre os quais devem ser implementadas as demais diretrizes ambientais eventualmente editadas no país.

Com relação ao ciclo de políticas públicas, foram analisadas as três fases iniciais do ciclo da PNMA: identificação do problema, formação de agenda e formulação de alternativas. Concernente às duas fases iniciais, os dados evidenciaram que, no cenário mundial, foi somente a partir da década de 70 que a temática ambiental passou de um "estado de coisas" para se tornar efetivamente um problema público. Seguindo a tendência mundial, é também neste momento que tiveram início, no Brasil, os contornos dos primeiros movimentos ecológicos. Este movimento, aliado à pressão externa exercida por organismos internacionais, no sentido da adoção de medidas para preservação ambiental, acabaram por culminar, em 1.981, com a edição da Lei 6.938/81, ocasião em que a temática ambiental passou a integrar formalmente a agenda política brasileira.

Com relação à terceira fase do ciclo de políticas públicas, pode-se afirmar que a PNMA foi estruturada por meio de princípios que fundamentam a gestão ambiental em nível nacional, com objetivos que orientam e conduzem as ações públicas na direção de um ambiente mais equilibrado, e por meio de instrumentos e mecanismos que possibilitam o alcance dos objetivos pretendidos - tudo isto articulado por meio de um sistema institucional, que integra as três esferas de poder no país, federal, estadual e municipal. 
Nesse sentido, a PNMA revela uma nova postura do governo brasileiro no trato das questões ambientais, já que, na perspectiva por ela trazida, a conciliação entre crescimento econômico e preservação ambiental não apenas é vista como possível, mas também desejável, sendo este o objetivo central em torno do qual se articula a política ambiental brasileira.

Para viabilização deste objetivo central, a PNMA lista uma série de objetivos específicos a serem alcançados com a política ambiental. Contudo, observa-se que não são traçadas metas concretas que permitam aferir, objetivamente, o alcance destes resultados. Neste aspecto, esta é uma limitação para a política pública em questão, especialmente no que tange ao seu monitoramento e posterior avaliação da eficácia da PNMA.

No que se refere aos mecanismos escolhidos pelo policymakers para assegurar o alcance dos objetivos propostos na PNMA, estão presentes na política pública instrumentos de premiação, de coerção e de conscientização. Reconhece-se que a política possui uma orientação relativamente mais coercitiva, já que os mecanismos de repressão predominaram no texto da lei, inclusive com a criminalização de condutas consideradas lesivas ao meio ambiente. Além do mais, a PNMA adotou a teoria da responsabilidade ambiental objetiva, um modelo mais severo de repressão dos danos ambientais.

Por fim, futuros estudos podem agregar novas variáveis às análises, adicionando, além de dados obtidos por meio de pesquisa bibliográfica e documental, também dados primários. Além disso, novos trabalhos que tenham como objetivo proceder à avaliação da PNMA podem servir como parâmetros para a melhoria e reformulação da política ambiental no país.

\section{REFERÊNCIAS}

ACSELRAD, Henri. Ambientalização das lutas sociais - o caso do movimento por justiça ambiental. Estudos Avançados, v. 24, n. 68, p. 103-119, 2010.

ANTUNES, Paulo de Bessa. Direito ambiental. 4. ed. Rio de Janeiro: Lumen Juris, 2000.

\section{ASSOCIAÇÃO BRASILEIRA DE NORMAS TÉCNICAS. Introdução à ABNT NBR ISO} 14001:2015. Rio de Janeiro: ABNT, 2015.

BARROS, Dalmo Arantes; BORGES, Luiz Antônio Coimbra; NASCIMENTO, Gleisson de Oliveira; PEREIRA, José Aldo Alves; REZENDE, José Luiz Pereira; SILVA, Rossi Alan. Breve análise dos instrumentos da política de gestão ambiental brasileira. Política \& Sociedade, v. 11, n. 22, p. 155-179, 2012.

BAUMGARTNER, Frank; JONES, Bryan. Agendas and instability in American Politics. Chicago: University of Chicago Press, 1993. 
BOZEMAN, Barry; PANDEY, Sanjey K. Public management decision making: effects of decision content. Public Administration Review, v. 64, n. 5, p. 555-565, 2004.

BRASIL. Anais da Câmara dos Deputados. Diário do Congresso Nacional. Exposição de motivos da Lei 6.938 de 31 de agosto de 1981. Brasília: Centro Gráfico do Senado Federal, ano XXXVI, n. 61, 1981. Disponível em: http://imagem.camara.gov.br/dc_20.asp?selCodColeca oCsv=J\&Datain=09/06/1981\&txpagina=1120\&altura=700\&largura=800\#/. Acesso em: 20 fev. 2020.

BRASIL. Lei 6.938, de 31 de agosto de 1981. Dispõe sobre a Política Nacional do Meio Ambiente, seus fins e mecanismos de formulação e aplicação, e dá outras providências. Disponível em: http://www.planalto.gov.br/ccivil_03/LEIS/L6938.htm. Acesso em: 20 fev. 2020.

CAIDEN, Naomi; WILDAVISKY, Aaron. Planning and budgeting in developing countries. New York: John Wiley, 1980.

CASTELLS, Manuel. O poder da identidade. São Paulo: Paz e Terra, 2008.

COBB, Roger W.; ELDER, Charles D. Participation in American Politics: the dynamics of agenda-building. Baltimore: Johns Hopkins University Press, 1983.

COHEN, Michael; MARCH, James; OLSEN, Johan. A garbage can model of organizational choice. Administrative Science Quarterley, n. 17, p. 1-25, 1972.

DROR, Yehezkel. Design for police science. New York: American Elsevier Pub. Co., 1971.

DYE, Thomas. Understanding public police. Englewood Cliffs: Prentice-Hall, 1972.

EASTON, David. A Framework for political analysis. Englewood Cliffs: Prentice Hall, 1965.

FARIA, Carlos Aurélio Pimenta de. Ideias, conhecimento e políticas públicas: um inventário sucinto das principais vertentes analíticas recentes. Revista Brasileira de Ciências Sociais, v. 18 , n. 51, p. 21-30, 2003.

FLICK, Uwe. Desenho de pesquisa qualitativa. Porto Alegre: Artmed, 2009.

FREY, Klaus. Políticas públicas: um debate conceitual e reflexões referentes à prática da análise de políticas públicas no Brasil. Planejamento e Políticas Públicas, n. 21, p. 211-259, 2000.

GELINSKI, Carmem Rosário Ortiz; SEIBEL, Erni José. Formulação de políticas públicas: questões metodológicas relevantes. Revista de Ciências Humanas, Florianópolis, EDUFSC, v. 42 , n. 1 e 2 , p. $227-240,2008$.

GORMLEY JÚNIOR, Willian T. Regulatory issue networks in a Federal system. Polity, v. 18, n. 4, p. 595-620, 1986.

GUSTAFSSON, Gunel. Symbolic and pseudo policies as responses to diffusion of power. Policy sciences, v. 15, n. 3, p. 269-287, 1983. 
HAM, Christopher; HILL, Michael. The policy process in the modern capitalist state. Brighton, Sussex, Wheatsheaf Books, 1985.

HECLO, Hugh. Policy analysis. British Journal of Political Science, v. 2, n. 1, p. 83-108, 1972.

HOWLETT, Michael; RAMESH, Michael. Come studiare le politiche pubbliche. Bolonha: II Mulino, 2003.

KOOIMAN, Jan. Modern governance: new government-society interactions.

Londres/California: Newbury Park Sage, 1993.

LANFREDI, Geraldo Ferreira. A objetivação da teoria da responsabilidade civil e seus reflexos nos danos ambientais ou no uso anti-social da propriedade. Revista de Direito Ambiental, $\mathrm{n}$. 6, ano 2, p. 87-96, 2001.

LASWELL, Harold D. Politics: Who gets hat, when, how. Cleveland, Meridian Books, 1936.

LIMA, Waner Gonçalves. Política pública: discussão de conceitos. Interface (Porto Nacional), n.5, p. 49-54, 2012.

LINDBLOM, Charles E. The science of muddling through. Public Administration Review, v. 19, p. 78-88, 1959.

LINDBLOM, Charles E. Still muddling, not yet through. Public Administration Review, v. 39, p. 517-526, 1979.

LOWI, Theodore J. American business, public policy, case studies, and political theory. Worl Politics, v. 16, n. 4, p. 677-715, 1964.

LOWI, Theodore J. The State in politics: the relation between policy and administration. In: NOLL, R. G. (org). Regulatory policy and the Social Sciences. Berkeley: University of California Press, 1985, p. 67-105.

MARQUES, Eduardo C. Estado e redes sociais: permeabilidade e coesão nas políticas urbanas no Rio de Janeiro. São Paulo: FAPESP; Rio de Janeiro: Revan. 2000.

MELO, Marcus André. Estado, governo e políticas públicas. In: MICELI, S. (Org.). O que ler na ciência social brasileira. v. 3: Ciência política. São Paulo e Brasília: Sumaré, Anpocs e Capes, 1999.

MÉNY, Yves. THOENIG, Jean-Claude. Le politiche pubbliche. Bolonha: II Mulino, 1991.

MILARÉ, Édis. Direito do ambiente: a gestão ambiental em foco: doutrina, jurisprudência, glossário. 6. ed. São Paulo: Revista dos Tribunais, 2009.

PASSOS, Priscilla Nogueira Calmon de. A conferência de Estocolmo como ponto de partida para a proteção internacional do meio ambiente. Direitos Fundamentais e democracia, v. 6, n.6, p. 1-25, 2009. 
PINHO, Carlos Tadeu Assumpção. O desafio da informação para formulação, monitoramento e avaliação de políticas públicas. Oficina 12. In: SEMANA DE ADMINISTRAÇÃO

ORÇAMENTÁRIA, FINANCEIRA E DE CONTRATAÇÕES PÚBLICAS, 8., 2011, Brasília. Anais [...]. Brasília: ESAF, 2011.

REGONINI, Gloria. Capire le politiche pubbliche. Bologna: II Mulino, 2001.

REIS, Elisa P. Reflexões leigas para a formulação de uma agenda de pesquisa em políticas públicas. Revista Brasileira de Ciências Sociais, v. 18, n. 51, 2003.

RUA, Maria das Graças; ROMANINI, Roberta. Para aprender políticas públicas. Volume 1: conceitos e teorias. IGEPP, Instituto de Gestão de Políticas Públicas, 2013.

SABATIER, Paul; JENKINS-SMITH, Hank. Policy change and learning: the advocacy coalition approach. Boulder: Westview Press. 1993.

SALHEB, Gleidson José Monteiro; NETO, Heitor de Azevedo Picanço; OLIVEIRA, Ivanci Magno; AMARAL JÚNIOR, Milton Ferreira; BOETTGER, Rafael José Cherfen; MONTEIRO, Vitória Cherfen de Souza; SUPERTI, Eliane. Políticas públicas e meio ambiente: reflexões preliminares. Revista Internacional de Direito Ambiental e Políticas Públicas. v.1, n. 1, p. 526, 2009.

SAMPIERI, Roberto Hernández; COLLADO, Carlos Fernández; LÚCIO, Pilar Baptista. Metodologia de pesquisa. 3.ed. São Paulo: McGraw-Hill, 2006.

SANTIAGO, Thais Muniz Ottoni. Análise de instrumentos da Política Nacional do Meio Ambiente. 2012. 149 f. Dissertação (Mestrado em Engenharia Florestal) - Universidade Federal de Lavras, Lavras, 2012.

SECCHI, Leonardo. Políticas públicas: conceitos, esquemas de análise e casos práticos. São Paulo: Cengage Learning, 2010.

SILVA, José Afonso da. Direito constitucional ambiental. 4. ed. São Paulo: Forense, 1995.

SILVA, Rogério Luiz Nery da. Políticas públicas e administração democrática. Sequência. Florianópolis, n. 64, p. 57-85, 2012.

SILVEIRA, Clóvis Eduardo Manliverni. A inversão do ônus da prova do dano ambiental difuso. In: LEITE, Jose Rubens Moratto. Aspectos processuais do direito ambiental. Rio de Janeiro: Forense Universitária, 2004.

SIMON, Herbert. A. Administrative Behavior: A Study of Decision-Making Processes in Administration Organizations. 2a ed.. New York: Macmillan. 1957. (Obra original publicada em 1947).

SOUZA, Celina. Políticas públicas: uma revisão de literatura. Sociologias, Porto Alegre, ano 8, no 16, p. 20-45, 2006.

SOUZA, Celina. Estado da arte da pesquisa em políticas públicas. In: Hochman, G; Arretche, M.; Marques, E. Políticas públicas no Brasil. Rio de Janeiro: Editora FIOCRUZ, 2007. 
VIOLA, Eduardo. O movimento ecológico no Brasil (1974-1986): do ambientalismo à ecopolítica. Revista Brasileira de Ciências Sociais, v. 3, n. 93, p. 5-26, 1987.

WILDAVSKY, Aaron. The policy of budgetary process. 2. ed. Boston: Little and Brown, 1992.

WILSON, James Q. American government: institutions and policies. Lexington MA, DC: Heat \& Co, 1983.

YIN, R.K. Case study research, design and methods (applied social research methods). Thousand Oaks. California: Sage Publications, 2009. 